\title{
TÁGIDES MINHAS E DELE: ECOS DE MARCIAL NA POESIA DE CAMÕES ${ }^{1}$
}

Fábio Paifer Cairolli

\begin{abstract}
RESUMO
O artigo pretende delinear ecos dos Epigramas do poeta latino Marcos Valério Marcial (c. 40c. 105 d.C.) na poesia de Luís Vaz de Camões (c. 1525-1580). Embora Camões nunca se declare leitor de Marcial, em pelo menos três passagens evoca-o: serão elas analisadas para investigar como ocorre a incorporação. Esperamos assim não apenas exibir fundamentos sobre o modo como Marcial era lido no século XVI, mas também exemplificar como autores do chamado "Classicismo renascentista" emulavam certos poetas antigos a que a historiografia literária posterior, por julgá-los menores, acabou por negar a eventual condição de modelo.
\end{abstract}

PALAVRAS-CHAVE: Marcos Valério Marcial (c. 40 - c. 105 d.C.); Luís Vaz de Camões (c. 1525-1580); poética; emulação.

\begin{abstract}
The article is designed to outline the echoes of the Latin poet Martial (c. 40 - c. 105 AD) in the poetry of Luís Vaz de Camões (c. 1525-1580). Although Camões never declared himself a reader of Martial's Epigrams, in at least three passages the Latin poet is clearly evoked: these passages will be examined, so as to make it possible to investigate how the incorporation occurs. We expect to show not only the way in which Martial was read in the sixteenth century, but also to provide an example on the way authors belonging to the so called "Renaissance Classicism" used to emulate some ancient writers to which later literary historiography, by considering them minor, denied the status of paradigm.
\end{abstract}

KEYWORDS: Martial (c. 40 - c. 105 AD); Luís Vaz de Camões (c. 1525-1580); poetics; emulation.

Investigar a presença de um autor da Antiguidade Clássica na literatura ocidental é, na maior parte das vezes, trabalho árduo. Certos autores estão de tal forma presentes nas literaturas modernas, que dificilmente se consegue avaliar totalmente sua recepção. Esta é a cautela que deve ter, por exemplo, quem pesquise a influência de Virgílio nos épicos modernos.

Estudar a presença de um poeta como Marcial na literatura de língua portuguesa é igualmente trabalhoso, mas por razões diversas: primeiro por não ter desfrutado entre historiadores da literatura latina e entre historiadores de outras literaturas por eles influenciados do mesmo prestígio de Virgílio; segundo, porque, ao contrário do que ocorre, por exemplo, na literatura de língua espanhola, Marcial é autor pouco citado em nossa língua, assim como o epigrama, único gênero de poesia que praticou, poucas vezes esteve entre os preferidos dos autores lusófonos. Uma das explicações deste

\footnotetext{
${ }^{1} \mathrm{O}$ artigo apresenta os primeiros resultados da análise da recepção de Marcial entre os autores de língua portuguesa, parte da pesquisa do meu doutoramento.

${ }_{2}^{2}$ Doutorando do Programa de Pós Graduação em Letras Clássicas, DLCV/FFLCH/USP.
} 
silêncio, pelo menos nos últimos 200 anos, pode-se ler num livro importante para compreender o pensamento português nos Oitocentos, o Verdadeiro método de estudar, de Luís Antônio Verney, publicado em 1746. O autor, em que pese à renovação que trouxe à mentalidade de Portugal naquele século, emite pesado juízo sobre Marcial:

Os Epigramas dos Gregos eram naturais, ainda que com graça: este estilo seguiu Catulo. Porém Marcial, no tempo dos Vespasianos, principalmente de Domiciano, que era a declinação [= declínio] da eloquência Latina e quase o princípio da idade de bronze, segundo os que entendem melhor foi o que começou a introduzir ou refinar as agudezas e equívocos nos Epigramas: o que agradou então [= naquele tempo], porque se começava na Corte a perder o bom gosto da Eloquência. Com efeito, alguns dos seus Epigramas podem passar [= ser aprovados] em obséquio daquele tempo e também do nosso, que ainda está alguma coisa ocupado com sutilezas: mas são raríssimos, e apostarei que não chegam a quinze, os bons. A maior parte, porém, são frialdades e parvoíces que os homens de juízo têm desprezado e reconhecem estar muito abaixo da nobreza de Catulo. Mureto, que imitou também Catulo, que parece o mesmo autor [= o próprio autor, Catulo], chama a Marcial "Bobo de Comédia", e o nosso Lílio Gregório Giraldo, a quem todos os doutos reconhecem por homem de juízo exatíssimo nestas matérias, diz deles com galantaria que só podem agradar aos asnos. (VERNEY, 1746, p.254, grifo nosso).

Neste duro juízo pode-se perceber o critério que diminui a apreciação de Marcial em Portugal: além de relacioná-lo ao mau gosto atribuído ao período em que viveu (e nota-se como está arraigada a discutível divisão da literatura em Idade de Ouro, Prata e Bronze), Verney julga, amparado por outras autoridades, que os epigramas de Marcial são majoritariamente "frialdades e parvoíces" porque refina "equívocos" e sobretudo “agudezas". Podemos aferir a gravidade da acusação de Verney contra Marcial se lembrarmos que o Verdadeiro método de estudar está em plena campanha precisamente contra a agudeza seiscentista, responsável, segundo crê, pela decadência da poesia portuguesa do seu tempo.

Podemos também medir o crime de que Marcial é acusado quando confrontamos o parecer de Verney com outro autor português que condena o poeta latino. Um século antes, o padre Antônio Vieira menciona Marcial no quarto capítulo do Sermão da primeira sexta-feira da quaresma, de 1644. Falando sobre o amor, Vieira afirma: "Entre os poetas, todos sabem o epigrama de Marcial: Ut ameris, ama. Deixo outras citações 
de autores desta casta, porque são gente que mais professa a lisonja que a verdade" (VIEIRA, 1855, p.196).

Parear lisonja e verdade como "profissão", isto é, declaração pública de um modo de pensar e agir, é significativa para compreender a ética de Vieira, na qual a verdade representa o desígnio divino (às vezes dolorosa, mas comprometida com a salvação da alma) ao passo que a lisonja é o recurso dos homens para obter benefícios terrenos, mas que não os absolve perante deus.

Sob este critério, Marcial, que escreve sobre "sutilezas" (Verney) e muitas vezes aborda as relações de clientelismo, inclusive com os imperadores, há de ser poeta que professa a "lisonja" (Vieira) e produz "equívocos" no leitor (Verney). As autoridades demonstram o quão inadequado era ler Marcial em terras portuguesas nos séculos XVII e XVIII, por afastar o leitor do que era moral e literariamente importante.

No entanto, Marcial não é ignorado, tendo sido aludido por vários autores portugueses, ainda que indireta e insolitamente. É o caso do príncipe dos poetas portugueses, Luís Vaz de Camões, que sem jamais mencionar Marcial, recorre algumas vezes a ele, por causa da matéria e de lugares-comuns, ou seja, para invenção, e por causa dos tropos, ou seja, para elocução. Deter-nos-emos aqui em quatro passagens.

Curiosamente, dos gêneros praticados por Camões aquele em que mais se evidencia a presença do epigramatista é a épica, os Lusíadas. Em outras palavras, embora Marcial escrevesse poesia classificável retoricamente ${ }^{3}$ como baixa ou humilde, foi apropriado no gênero mais elevado praticado por Camões, o que demonstra que, na leitura do século XVI segundo os fins para os quais foi apropriado, não importou a distância que, para os latinos, havia entre este poeta e os épicos.

Outro aspecto digno de nota é que as passagens dos Lusíadas em que ocorrem as menções pertencem à proposição, no Canto $\mathrm{I}$, e ao excurso final do Canto $\mathrm{V}$, partes em que, suspensa a narração, dá-se voz ao narrador. Estas são passagens importantes para compreender o sistema poético camoniano.

A primeira que analisaremos é a terceira estância do Canto I:

\section{Cessem do sábio Grego e do Troiano}

\footnotetext{
${ }^{3} \mathrm{O}$ modelo mais conhecido deste tipo de leitura entre os antigos é da Poética, (1448a), em que Aristóteles classifica gêneros de poesia pelo caráter (éthos) e ações (práxeis) superiores, semelhantes ou inferiores das personagens em relação a nós, homens médios. Marcial vincula o epigrama aos homens comuns, em oposição aos deuses e heróis das poesias épica e trágica, como o X, 4.
} 
As navegações grandes que fizeram;

Cale-se de Alexandre e de Trajano

A fama das vitórias que tiveram;

Que eu canto o peito ilustre Lusitano,

A quem Neptuno e Marte obedeceram:

Cesse tudo o que a Musa antiga canta,

Que outro valor mais alto se alevanta.

Estamos no início do poema, bem na proposição da matéria: Camões sugere aqui que, preteridas as viagens e combates dos antigos cantos épicos, sejam cantados os feitos dos heróis portugueses. Conforme nota Pereira (2008, p.94), esta passagem insere-se na tópica, cara aos autores do século XVI, do calar os feitos antigos superados pelos modernos. A tópica expõe a ambiguidade com que o homem renascentista se relacionava com o antigo: era respeitável e modular, mas digno de ser superado.

A mesma relação, contudo, era tomada à Antiguidade: lá não apenas o vínculo dos poetas gregos e romanos com o passado se estabelecia como "emulação", senão que ocorria o próprio tópico de calar o antigo à face do moderno. Assim, quando Camões propõe cantar a vitoriosa modernidade, está imitando os modelos antigos que diz superar, particularmente o primeiro epigrama do Livro dos espetáculos de Marcial:

Barbara pyramidum sileat miracula Memphis Assyrius iactet nec Babylona labor; nec Triviae templo molles laudentur Iones, dissimulet Delon cornibus ara frequens; aëre nec vacuo pendentia Mausolea laudibus inmodicis Cares in astra ferant. omnis Caesareo cedit labor Amphitheatro, unum pro cunctis fama loquetur opus.

Cale Mênfis inculta o valor das pirâmides, Não jacte o assírio o esforço babilônio, Nem frouxos jônios louvem o templo de Trívia; Delos esconda o altar com muitos chifres, Nunca, elevado no ar vazio, o Mausoléu, Imoderado, o cário ao céu levante.

Todos o Anfiteatro de César supera, Que terá a fama das demais somadas. ${ }^{5}$

Os excertos têm nada menos do que três vínculos:

1) a sinonímia dos verbos sileat, "cale", v. 1, e "cale-se", v. 6;

\footnotetext{
${ }^{4}$ A explicação mais alentada de imitação e emulação ocorre no pseudo-Longino, Sobre o sublime, XIII e XIV. Mas Dionísio de Halicarnasso, no Tratado da imitação, III, diz: "A imitação é uma atividade que, segundo alguns princípios teóricos, refunde um modelo. A emulação, por sua vez, é uma atividade do espírito que o move no sentido da admiração daquilo que lhe parece belo" (1986, p.40).

${ }^{5}$ As traduções dos epigramas de Marcial aqui apresentadas são de nossa autoria.
} 
2) a sinédoque fama/altura: "Que outro valor mais alto se alevanta", e "in astra ferant" ("ao céu levante"); mas principalmente

3) o conceito de "superação da soma dos demais": Marcial propõe que só o Coliseu (o Anfiteatro de César) terá a fama de todas as grandes construções ("unum pro cunctis", v. 8); Camões pede que cesse tudo, v. 7, o que é cantado pela musa antiga.

Imitar de Marcial este tópico foi importante para realçar certos aspectos do seu poema épico. O Livro dos espetáculos é coletânea de poemas sobre a inauguração do Coliseu no ano 80 de nossa era. Antes de descrever os espetáculos propriamente ditos, Marcial descreve como o Anfiteatro, construído bem onde antes havia o palácio do tirânico e terrível Nero, foi então devolvido aos romanos. Conta também como todos os povos submetidos ao império se uniam no anfiteatro e como os espetáculos glorificavam o povo romano inteiro na pessoa do imperador ${ }^{6}$.

Tal perspectiva representa como que uma "ideologia de Estado" diferente da que representa a Eneida de Virgílio, que é o modelo imediato de Camões. A Eneida narra a história da fundação da Roma pelo herói Eneias e o destino de ser governada por um descendente dele, Augusto. O Livro dos espetáculos narra a fundação de uma "nova" Roma, agora governável só porque o imperador era aclamado pelo povo precisamente no Anfiteatro, que assim tolheu ao fórum a prerrogativa de ser o ponto de encontro do povo romano.

Assim vista, a perspectiva de Marcial interessa à finalidade epidítica de Camões, em que o herói Vasco da Gama personifica a totalidade do povo português e leva ao Oriente a fé, a mesma fé que dera aos portugueses o governante bom e pio, D. Sebastião. O modo como D. Sebastião é enaltecido ao mesmo tempo como promotor e resultado da fé do povo português ${ }^{7}$ é análogo ao modo como o poder dos imperadores é descrito por Marcial, quer no Livro dos espetáculos, quer nos doze livros de Epigramas.

Ainda no primeiro canto, em trecho anterior ao início da narração, outra passagem aproxima-se da poesia de Marcial. Referimo-nos à estância 9:

Inclinai por um pouco a majestade, Que nesse tenro gesto vos contemplo, Que já se mostra qual na inteira idade,

\footnotetext{
${ }^{6}$ Livro dos espetáculos, poemas 3 e 5 respectivamente.

${ }^{7}$ Em I, 6, v. 5-8, Camões descreve o rei D. Sebastião da seguinte forma:

Maravilha fatal da nossa idade, Dada ao mundo por Deus, que todo o mande, Para do mundo a Deus dar parte grande.
} 
Quando subindo ireis ao eterno templo;

Os olhos da real benignidade

Ponde no chão: vereis um novo exemplo

De amor dos pátrios feitos valerosos,

Em versos divulgado numerosos.

Aqui, Camões dirige-se a D. Sebastião ainda jovem para oferecer-lhe o poema à leitura. Em diversos pontos, esta estrofe assemelha-se ao epigrama I, 4 de Marcial:

Contigeris nostros, Caesar, si forte libellos, terrarum dominum pone supercilium.

Consueuere iocos uestri quoque ferre triumphi, materiam dictis nec pudet esse ducem.

Qua Thymelen spectas derisoremque Latinum, illa fronte precor carmina nostra legas.

Innocuos censura potest permittere lusus: lasciua est nobis pagina, uita proba.

Se pegas meus livrinhos, César, por acaso, Desfranze o cenho de senhor das terras.

Teus triunfos ${ }^{8}$ também são afeitos aos risos, Não peja ao chefe ser tema das falas.

Como vês Tímele e Latino com seus mimos,

Lê com tal rosto, eu peço, meus poemas.

Pode a censura permitir inócuos jogos:

Lascivo é meu papel, a vida é proba.

Marcial revela-se, para o propósito da passagem camoniana, fonte abundante de tópicos. A nosso ver, isso ocorre particularmente porque aquele poeta é um dos que mais abertamente amplifica o tema do louvor ao governante por meio de hipérbole ${ }^{9}$. O primeiro tópico é propor que o governante, para ler o que se lhe oferece, deponha o gesto que é a insígnia de que é poderoso (pone terrarum dominum supercilium, "Desfranze o cenho de senhor das terras", v. 2, "Inclinai por um pouco a majestade", v. 1). Ambos são descritos no auge da glória, mesmo que ela ainda não exista no momento da alocução: Domiciano é recordado no desfile triunfal que os generais vencedores promoviam em Roma, glória máxima que um militar poderia receber (e deve-se notar que em essência o imperador romano é comandante militar); D. Sebastião é visto como se já fosse o homem que, coberto de glórias, ascenderia aos céus (glória máxima para um governante católico e confirmação do casamento entre monarquia e fé). Na imagem construída por Camões, é notável como a hipérbole é produzida por antecipação:

\footnotetext{
8 "Triunfo" (triumphi) ainda é aqui o desfile triunfal, decorrente da vitória militar.

${ }^{9}$ A amplificação é colocada como a característica principal em um discurso de elogio ao governante, conforme é exposto, no século III, por Menandro, o Retor.
} 
quando o poema foi publicado em 1572, D. Sebastião é jovem de 18 anos que ainda não realizou nenhum feito digno de memória, o que não impede que o poeta, ao ressaltar as virtudes intrínsecas do rei, já veja na feição do governante as empresas que o tornarão digno do céu - as empresas que, apesar da grande expectativa da nação, acabam não ocorrendo, dado o precoce desaparecimento do rei aos 24 anos.

A passagem é também exemplo de profissão de fé: a justificação que o poeta dá para pedir que o rei aprove a obra é a utilidade da matéria ao próprio rei, que se verá engrandecido por ser senhor de um povo excelente. Uma vez que a estrofe camoniana descreve o que é a matéria da épica (os "pátrios feitos valerosos"), é digna de nota a menção à extensão do poema ("versos numerosos"), motivo de preocupação de epigramatistas como Marcial, não de épicos. Com efeito, não se menciona extensão nos versos prefaciais da Ilíada e da Odisséia, de Homero, nem na Eneida, de Virgílio, nem no Orlando furioso, de Ariosto, principais épicos imitados por Camões e aludidos na abertura dos Lusíadas.

A última passagem dos Lusíadas que pretendemos analisar é o excurso final do canto V, da estrofe 94 a 99:

94

Trabalha por mostrar Vasco da Gama

Que essas navegações que o mundo canta

Não merecem tamanha glória e fama

Como a sua, que o Céu e a Terra espanta.

Sim, mas aquele Herói que estima e ama

Com dões, mercês, favores e honra tanta

A lira Mantuana, faz que soe

Eneias, e a Romana glória voe.

95

Dá a terra Lusitana Cipiões,

Césares, Alexandros, e dá Augustos;

Mas não the dá contudo aqueles dões

Cuja falta os faz duros e robustos.

Octávio, entre as maiores opressões,

Compunha versos doutos e venustos

(Não dirá Fúlvia, certo, que é mentira,

Quando a deixava António por Glafira).

96

Vai César, subjugando toda França,

$\mathrm{E}$ as armas não lhe impedem a ciência;

Mas, numa mão a pena e noutra a lança, 
Igualava de Cícero a eloquência.

O que de Cipião se sabe e alcança,

É nas comédias grande experiência.

Lia Alexandro a Homero de maneira

Que sempre se lhe sabe à cabeceira.

97

Enfim, não houve forte Capitão,

Que não fosse também douto e ciente,

Da Lácia, Grega, ou Bárbara nação,

Senão da Portuguesa tão-somente.

Sem vergonha o não digo: que a razão

De algum não ser por versos excelente,

É não se ver prezado o verso e rima:

Porque quem não sabe arte, não na estima.

98

Por isso, e não por falta de natura,

Não há também Virgílios nem Homeros;

Nem haverá, se este costume dura,

Pios Eneias, nem Aquiles feros.

Mas o pior de tudo é que a ventura

Tão ásperos os fez e tão austeros,

Tão rudos e de engenho tão remisso,

Que a muitos lhe dá pouco ou nada disso.

99

Às Musas agradeça o nosso Gama

O muito amor da Pátria, que as obriga

A dar aos seus, na lira, nome e fama

De toda a ilustre e bélica fadiga:

Que ele, nem quem na estirpe seu se chama,

Calíope não tem por tão amiga,

Nem as filhas do Tejo, que deixassem

As telas de ouro fino, e que o cantassem.

A passagem, que encerra a longa narração empreendida por Vasco da Gama, é relevante a nossos propósitos por acumular diversos vínculos com a poesia de Marcial. O primeiro e mais óbvio está na estrofe 95, versos 5-8, em que Camões menciona os poemas venustos de Otávio. Estes versos aludem ao epigrama XI, 20 de Marcial, em que o poeta, confrontando-se com leitores que o criticavam pela linguagem lasciva, insere no poema seis versos escritos por Augusto, que referem com turpilóquio o triângulo amoroso de Fúlvia, Antônio e Glafira. Como não sobreviveu nenhuma coletânea de escritos de Augusto, a fonte dos seis versos, autênticos ou não, é a citação de Marcial. 
Outro vínculo das estrofes com Marcial é a maneira como referem a poesia de Virgílio e em particular o desencanto com a vida de poeta. Embora desencanto em outros passos de Camões diga respeito a Ovídio, especialmente por causa do desterro, é ele um dos temas mais bem desenvolvidos da poesia de Marcial. Um epigrama é de especial interesse para compreender a questão, o VIII-56 $6^{10}$, por tratar tanto do desengano do poeta como da leitura da poesia virgiliana:

Temporibus nostris aetas cum cedat auorum creuerit et maior cum duce Roma suo, ingenium sacri miraris desse Maronis nec quemquam tanta bella sonare tuba.

Sint Maecenates, non deerunt, Flacce, Marones Vergiliumque tibi uel tua rura dabunt. iugera perdiderat miserae uicina Cremonae flebat et abductas Tityrus aeger oues: risit Tuscus eques paupertatemque malignam reppulit et celeri iussit abire fuga.

"Accipe diuitias et uatum maximus esto; tu licet et nostrum" dixit "Alexin ames."

Adstabat domini mensis pulcherrimus ille marmorea fundens nigra Falerna manu,

et libata dabat roseis carchesia labris quae poterant ipsum sollicitare Iouem.

Excidit attonito pinguis Galatea poetae Thestylis et rubras messibus usta genas: protinus Italiam concepit et "Arma uirumque," qui modo uix Culicem fleuerat ore rudi.

Quid Varios Marsosque loquar ditataque uatum nomina, magnus erit quos numerare labor?

Ergo ero Vergilius, si munera Maecenatis des mihi? Vergilius non ero, Marsus ero.

Embora ao nosso tempo ceda o dos avós e a grande Roma cresça com seu chefe, te espanta a falta de um Marão de sacro engenho ou de quem cante a bélica trombeta.

Não faltarão Marões se houver Mecenas, Flaco, e até teus campos te darão Virgílios.

Perdera as terras da infeliz Cremona Títiro e chorou de aflição pelas ovelhas.

O cavaleiro etrusco riu, a má pobreza repeliu e ordenou ligeira fuga.

"Recebe os bens e o maior vate serás", disse, "E até podes amar o nosso Aléxis".

Perto da mesa do senhor, mui belo, estava a verter, com marmóreas mãos, falerno, e dava os copos que provou com lábios róseos

\footnotetext{
${ }^{10}$ A tradução consta em nossa dissertação de mestrado Pequena gramática poética de Marcial, p. 160.
} 
que até perturbar Júpiter podiam.

Esqueceu Galateia o poeta, admirado, e Téstile, queimada nas colheitas.

Rápido, a Itália concebeu e o "Canto as armas..." a rude voz que mal cantara $A$ Mosca" .

Por que falar em Vário e Marso e em ricos nomes de vates que citar dará trabalho?

Serei Virgílio se os presentes de Mecenas deres? Virgílio não, mas serei Marso.

Deste poema provém a sinédoque Virgílios no plural, significando "poetas épicos", utilizada também por Camões, outro vínculo entre os excertos, mediante o qual o epigrama pôde ser utilizado como argumento complementar ao seu. Para Marcial, nem mesmo Virgílio teria tido condições de ser um Virgílio (isto é, poeta épico), não fosse a existência de Mecenas. Sem Mecenas, Virgílio é apenas um aldeão de rude voz, cantor de poemas bucólicos. O argumento de Marcial, como em diversas passagens da obra, visa a obter favores econômicos de algum amigo mais abastado. Já na passagem camoniana, toda a defesa da arte, um dos apanágios da cultura humanista do poeta, e da importância das letras mesmo entre generais oculta outra questão, que apenas na última estrofe se deixa entrever: quando fala das Musas que amam a pátria e não Vasco da Gama ou seus descendentes, está referindo-se a si mesmo que, provavelmente, teve recusado um pedido de proteção à família do navegador.

Vimos exemplos de como Camões em certos passos imita Marcial. Em linhas gerais, nota-se que o poeta português usa do modelo latino não servilmente. À matéria alheia dá forma própria para fins específicos e ao fazê-lo não se pretende menor que qualquer outro poeta da tradição em que se insere. Este modo de relacionar-se com o legado tradicional, que os antigos chamavam imitação e emulação, não se confunde com mero plágio de temas e imagens da Antiguidade, mas diz respeito ao desejo de, reelaborando material comum, tentar ser o mais bem sucedido autor no juízo dos leitores. A expressão mais conhecida de tal proceder provém de Pseudo-Longino:

Esta prática não constitui furto; é como um decalque de belos sinetes, de moldados ou de obras manuais. Parece-me que Platão não faria abrolhar tão belas flores entre pontos doutrinários da filosofia, nem acompanharia amiúde a Homero nas selvas da poesia e das expressões, senão, por Zeus! para, de

\footnotetext{
${ }^{11}$ Culex (A Mosca) é poema que parodia a épica heroica e integra Appendix vergiliana, coletânea que reúne poemas jocosos antes atribuídos a Virgílio.
} 
corpo e alma, disputar com ele a primazia, como um competidor jovem em frente de um lutador já de muito admirado (ARISTÓTELES et al., 2003, p.85-86, grifo nosso).

Nas passagens estudadas a imitação não é explícita: não mencionando o poeta tomado por modelo, o lugar-comum utilizado só é identificável ao leitor apto, isto é, àquele que compartilha o mesmo cabedal literário. Este tipo de imitação faz que o poema tenha outra camada de sentidos, além dos expressos literalmente. Exemplo disso é a sinédoque "Virgílios" (Marones, v. 5), usada por Marcial no epigrama VIII-56 e ampliada para Virgílios e Homeros em Camões (V, 98, 2). Ao recorrer a uma passagem notória, Camões recupera o sentido inteiro dela: não ousa defender tão abertamente o mecenato, o incentivo às letras, nem seria decoroso censurar os herdeiros do herói que ele canta, mas, ao fazer que o leitor douto se lembre de Marcial, inclui a franqueza com que o poeta trata o tema e acrescenta os argumentos e a autoridade dele aos seus.

\section{Referências Bibliográficas}

ARISTÓTELES; HORÁCIO; LONGINO. A poética clássica. Trad. Jaime Bruna. São Paulo: Cultrix, 2003.

BERARDINELli, Cleonice. "Camões, dez anos depois". SemeaR: cátedra Padre Antônio Vieira de estudos portugueses, 10, 2004.

CAIROLli, Fabio Paifer. Pequena gramática poética de Marcial. Dissertação de Mestrado. São Paulo: FFLCH-USP, 2009, inédita.

CAMÕES, Luís Vaz de. Os lusíadas. Lisboa: Verbo, 1972.

DIONÍSIO DE HALICARNASSO. Tratado da imitação. Ed. Raul Miguel Rosado Fernandes. Lisboa: Instituto Nacional de Investigação Científica/Centro de Estudos Clássicos da Universidade de Lisboa, 1986.

MARTIALIS, Marcus Valerius. Epigrammata: recognouit breuique adnotatione critica instruxit. Oxford: Clarendon Press, 1987.

MENANDER RHETOR. Menander Rhetor. Trad. D. A. Russel; N. G. Wilson. Oxford: Clarendon Press, 1981.

PEREIRA, B. F. "Antigos e modernos: o humanismo norte-europeu nas retóricas peninsulares do séc. XVI". Península: revista de estudos ibéricos, 5, p.93-101, 2008. 
[VERNEY, Luís Antônio]. Verdadeiro método de estudar. Valença: Antonio Balle, 1746.

VIEIRA, Pe. Antonio. Sermões do Padre Antonio Vieira. Vol. V. Lisboa: J. M. C. Seabra e T. Q. Nunes, 1855. 